\title{
Is Virtual Reality a Memorable Experience in an Educational Context?
}

\author{
$\underline{\text { doi:10.3991/ijet.v6i1.1433 }}$ \\ T. Nadan, V.N. Alexandrov, R. Jamieson and K.A. Watson \\ University of Reading, Reading, UK
}

\begin{abstract}
Learning science concepts are very often challenging, especially when complex concepts are involved. Teachers have recourse to many different types of teaching methods which are however limited when it comes to explaining students about three dimensionality concepts. With these limitations, the teaching methods fall short in increasing the interest of students. It is therefore important to understand how the new generation learns and hence to teach them accordingly. Virtual Reality (VR) is an emerging technology which can be used for teaching science concepts. VR is innovative and hence easily captures students' interest. This paper presents the results of some preliminary studies conducted with a view to showing the extent to which VR is a memorable experience for students, in order to support its use for teaching Science, Technology, Engineering and Mathematics (STEM) concepts.
\end{abstract}

Index Terms-Memorable experience, STEM education, Virtual Reality.

\section{INTRODUCTION}

Advance in technology has speeded up the general way in which students learn. To keep in pace with this change in the learning process, different teaching strategies have had to be employed in school. Learning and teaching changed from a book-based approach, to a more pictorial and group work approach and later on adopted instructional technologies such as projectors, PowerPoint presentations, advanced calculators and computer conferencing, to name a few. The book-based approach is a traditional pedagogical method which involves a passive way of learning while the pictorial and group work includes active learning through hands-on activities, two-dimensional (2D) models and group projects, among others. A more advanced learning methodology is via the instructional technologies. These mainly include e-learning technologies which make use of computer technologies such as internet access, networking, modelling softwares and Virtual Reality (VR), among others [1]. E-learning technologies provide more cooperation and collaboration between students, research works and web-based activities. These technologies are similar to the ways students gather information and communicate outside school hours [1]. In fact, according to a 2008 report by OfCom, $27 \%$ of age group 15-24 use a personal computer with internet access for TV viewing, $45 \%$ use it watch video clips and $52 \%$ download music, videos, clips and files [2]. This shows that students feel culturally comfortable with the elearning technologies, which are thus easily accepted in schools.

In this paper we propose the use of cutting edge technologies along side traditional teaching methods as a means to enhance learning, specifically in Science, Technology, Engineering and Mathematics (STEM) subjects. In fact, it has been shown that retention of newly acquired knowledge increases by ten times when the new knowledge is put into use [3]. Virtual Reality (VR) is in line with this active learning process and the study conducted evaluates what students remember the most when subjected to various new instructional technologies which extrapolate from theoretical concepts that they have studied in the classroom. As the old saying by Conficius states: 'I hear and I forget; I see and I remember; I do and I understand', we wanted to lay emphasis on experimental education as a means to enhance learning and allow students to explore these concepts. The paper will outline the learning process and some benefits of technologies in education and elaborate on a set of preliminary tests carried out to investigate how memorable VR is in an education context. The results obtained from these tests will be presented and discussed to show how VR can help in STEM education.

\section{THE LEARNING PROCESS}

Learning is a generic term which refers to the acquisition of knowledge. Prior to teaching any group of students, it is imperative for teachers to know about the learning process. Once comprehension of the learning process is gained, teachers must then understand how a particular age group or an individual learner best acquires information, processes the newly acquired information and how this information is best remembered by the learner. This can be achieved through assessing two criteria, namely: learning style and learning modality, from the students' perspectives.

Willing defines learning style as being one's natural, usual and preferred way of learning [4]. Kolb describes the learning process and learning style as consisting of a cycle of four inter-related stages: concrete experience; observation and reflection; abstract conceptualization and generalization; and active experimentation. Concrete experience focuses on direct experiences, that is, the 'first person' experiences. Reflective observation occurs through studying others, the learner engages fully into the learning of new experiences without any bias. Abstract conceptualization involves the creation of new concepts based on the observations made in order to form a logical theory. Active experimentation, on the other hand, is an approach of putting concepts into practice. It lays emphasis on the importance of experience in the learning process and makes use of the logical theories defined in the previous step, for problem solving and decision making [5, 6].

According to Willing [4], the learning style is influenced by one's cognitive skills, socio-cultural back- 
ground, educational instruction and experiences and finally by one's personal strengths, weaknesses and capabilities. In [7], the authors state that the use of learning models will help teachers to enhance the students' ability to learn.

The second criterion, learning modality, further defines four groups of factors, namely: auditory, visual, tactile and kinesthetic. Unlike auditory learners whose retention is focused on listening to the teacher or to their own voice, visual learners learn best by visualizing objects or mentally creating objects to match descriptions. Tactile learners, on the other hand, prefer to touch and play around with objects, while kinesthetic learners mostly adopt a concrete experiential approach, whereby simulations, explorations and problem-solving are preferred.

Identification of the learning style and learning modality of a particular age group involves very much understanding the lifestyle of students, so that communication of knowledge is perceived correctly. Understanding of newly acquired information is a key aspect to retention of that newly acquired knowledge. The current generation students have shifted from being the traditional auditory learners to being more visual, tactile and kinesthetic learners. Being more inquisitive in nature, the new generation students prefer to see what they are learning and experience the newly acquired knowledge. Previous knowledge is combined with first person experience to positively influence understanding and future [8]. As a matter of fact, the authoritarian way of teaching no more has its place it this new era and instead teaching is more student-centred process. Educators have changed from being knowledge givers to knowledge facilitators [9]. However, though importance must be given particularly to the learner; the educator, organization and content are also important factors to bear in mind [3].

\section{UsE OF TECHNOLOGIES IN THE LEARNING PROCESS}

According to Albright et al. [10], instructional technologies have various benefits. For instance instructors can teach students tasks which cannot be shown or reproduced in the classroom, such as molecular structures, which are too small to visualize with the naked eye. Additionally, in the information age, instructional technologies help students to understand their surroundings better and to face real world challenges better. For example, pinhole cameras can be used to teach how the concept of light and why image is inverted in a camera [11]. According to Wiske [12], when being used by knowledgeable educators to support learning, instructional technologies can bring a huge improvement in the teaching and learning processes. Also, these technologies help in faster communication and processing, hence increasing productivity. For instance, instead of spending time solving equations and plotting graphs for data, advanced calculators provide easy display of mathematical functions and graphs, giving the student more time to assess, interprete and understand the graphical representations [12]. When used in an effective way, instructional technologies increase students' interest and stimulate comprehension [13, 14]. In 1999, Bain et al. conducted a study whereby students subjected to technology-based teaching methods had an average of 94 points more in the SAT-I than those who had the traditionalbased method [15]. Another study on the impact of educational technology on student achievement proved that the use of computer-assisted or computer-mediated instruction supports student learning to a greater extent compared to those without any access to these technologies [16]. Additionally, instructional technologies help in networking and collaboration among students, between the teacher and the student and also collaboration with other group of students and teachers in different schools.

Now that learning and instructional technologies have been explained, another question that crops up for teachers is 'how to use instructional technology for teaching science?'. Learning of sciences differs somewhat from the general learning process. Ebenezer et al. described the constructivism theory as being used as an interactive mode for science learning and teaching [11]. This theory takes into consideration that a student makes use of his/her own beliefs and experiences to acquire knowledge. According to Piaget [17], learning is constructed in the learner's mind. In 1977, Karplus [18] developed a learning cycle based on the Piagetian principle. Karplus' learning cycle includes exploration, explanation and application [11]. The exploration phase allows students to perform experiments about concepts which they do not know before hand. This is followed by the explanation phase, whereby the student explains his/her understanding and the teacher gives further explanation about the observed phenomena in the experiment, relating the different scientific concepts involved to the observation made. Finally, the application phase involves the use of the newly learnt concepts to more situations

The rapid technological boom has reshaped the way students acquire knowledge and learn and has added additional requirements on teaching and learning to make students more prepared for future technological challenges and we believe that instructional technologies can be taken one step ahead by integrating Virtual Reality (VR) as a teaching and learning aid for students.

\section{WHAT IS VIRTUAL REALITY?}

Virtual Reality is a three-dimensional (3D) simulation of a real or imaginary system. Users of such a system can often manipulate virtual objects in the simulated environment, with the effects being rendered in real time. Immersion and presence are two important concepts which are often used to describe the extent of virtuality of VR systems. The former is described as the deepness of a user's experience in a virtual environment, while presence is a subjective feeling of being in an environment when the person is physically in another environment [19]. These two terms have significant impact on users' behaviour in a virtual environment and are critical in differentiating the various VR technologies that exist, some of which will be discussed in the following subsection.

\section{A. Some Virtual Reality Systems}

Desktop systems provide the lowest level of immersion and are therefore commonly referred as non-immersive systems. These systems are developed to be used on a simple desktop PC with good graphics cards and simple monitor. They involve little or no interaction with the virtual system. Simple keyboard strokes or mouse can be used to perform basic operations, though a 3D mouse and joystick can be used for navigation and a SpaceBall or data glove for enhanced interaction. Besides, 3D vision can be achieved using shutters glasses. Since interaction is limited and the users are not inside the virtual world, desktop VR systems offers little immersion and presence. 
A more relevant VR system to the study undertaken is the PowerWall. This is a large high-performance and high-resolution screen which is rear projected. It uses a technique of polarized images and hence requires polarized glasses for viewing the 3D images. PowerWalls are ideal for large group viewing and provides viewing of virtual objects of larger scales compared to the desktop systems. This is particularly important in this study as the enlarged view provided by the PowerWall highlights important details, such as molecular information which would otherwise be difficult to spot on a small desktop monitor. This is significant in providing a higher level of immersion as compared to the desktop VR systems.

The Cave Automatic Virtual Environment (CAVE) [20] is a far end VR technology which provides increased immersion and presence. Unlike the other VR systems described above, the CAVE provides a room-like surrounding virtual environment. Users of such a system are able to walk into the environment. Navigation and manipulation of virtual objects can be achieved using a special device called a wand or gloves while $3 \mathrm{D}$ visualization requires 3D shutter glasses, which show the depth of virtual objects, hence $3 \mathrm{D}$ vision. In addition to successfully obscuring the user from the real world, the CAVE also provides a good environment for group viewing and is commonly used for collaborative projects. The CAVE is particularly relevant to teaching of science subjects such as Chemistry and Biology, where understanding of complex 3D information is critical.

\section{B. Benefits of Virtual Reality in Teaching and Learning}

VR provides various beneficial aspects for the enhancement of education and the most important of these is that VR transcends the visual limitations of traditional teaching methods. The human eyes have a total view between $160^{\circ}$ to $208^{\circ}$ and any technology that provides a large field of view within or exceeding this range is likely to increase the way that our mind processes what we see. With a field of view of $360^{\circ}$, the CAVE is an excellent way of increasing visual perception, which subsequently increases understanding of what we see. In an educational context, if students are able to perceive 3D images of abstract concepts, this will inevitably increase their perception and hence their understanding of these concepts.

Likewise, VR can increase understanding by providing visualization on large scale. Both the PowerWall and the CAVE are large and can highlight miniscule details which would otherwise be unseen by the naked eye. This attribute of CAVEs and PowerWalls are important to particularly show molecular structures to students. Although projectors and microscopes can serve for the same purpose, VR systems have the additional benefit that they can provide user interaction and manipulation with virtual objects. For instance, in a CAVE, students can walk around in a molecular structure and rotate the virtual molecule in different angles for better observations.

Besides, VR provides an intuitive way of learning by focusing on the first person experience. This is particularly important in the learning process. Unlike "third person" experience, "first person" experience is subjective [21]. For instance, students do not have to learn through the experience of their teachers, they can instead acquire knowledge by first person experiences. According to Youngblut [22], experience helps students to retain and generalize new knowledge in a more effective way. VR provides the right platform for immersing students into a virtual environment and helps them to learn better. In fact, immersion in a virtual environment is a new form of experience [23].

VR has positive cascading effects on students as the first person experience is so intuitive and captivating and it motivates students to further investigate on what they are learning. This can enhance learning as students feel more engaged in what they are doing and hence students become more enthusiastic and learning is more fun. In fact, student motivation increases when they are subjected to interesting things to learn and new information [8]. The high tech side of VR satisfies the needs of the new generations and motivates students to learn by curiosity, which an intuitive way of learning for the new generations.

In the educational framework, VR also proves useful in enhancing learning of concepts which cannot be observed easily in the real world. While in some cases it would be very hazardous to learn by doing, VR systems provide a safer environment where students can repeatedly run simulations without any hazardous consequences. This is particularly helpful for training medical students to perform surgery. Safer simulations can also be done for situations where it would be costly to perform the actual simulation.

\section{STUdies CONDUCTED}

Based on the various works carried out by other researchers, there was sufficient proof that VR can be beneficial in the learning process. The areas of interest in this study are active experimentation learning and visual learning mode. The basic aim was to assess how well students could remember concepts which they are aware of theoretically but have never seen / experienced before.

The study undertaken involves subjecting students of a particular age group to various new technologies which are helpful for a better understanding of what they have learnt in school and to later on assess the extent to which these students can remember these technologies. The age group chosen for the study was the year 12 and 13 Biology and Chemistry students from a Reading local school, Kendrick School since it specialises in Science and Mathematics. This group of students has been chosen for this preliminary study to emphasis Science, Technology, Engineering and Mathematics (STEM) education and how VR can enhance STEM learning.

The study itself consisted of a 3 hours visit divided into demos. These were clearly categorized as VR (CAVE and PowerWall) and biology laboratory (Microscopy and Imaging Unit, Mass Spectrometry, Structural Biology Unit / Transcriptomics) demos, each presented individually in a different room. Each laboratory and virtual reality demo was kept to only 20 minutes, based on the fact that the attention span of an average student is limited to approximately 15 minutes. The demonstrators were specific in not speaking too technically to the students so that the students to do lose interest in what they were seeing. To make students feel more comfortable, they were always accompanied with their teachers who were helpful in relating the different laboratory equipments and molecular visualizations to the various concepts the students have encountered in their classes.

For the biology laboratories, different technologies relevant to the subject group's academic curriculum were 
chosen. These technologies provided the students with a better understanding of mass spectroscopy, DNA sequencing, microscopy techniques and different experimental phases.

The CAVE and PowerWall demos focused on biology topics which were previously identified by the teachers as most interesting and most helpful for the students to grasp the theoretical concepts being taught at school and these included protein structure and function. Shutter glasses and wands were used for the CAVE for $3 \mathrm{D}$ visualization and manipulation respectively, while students were given polarized glasses to view the $3 \mathrm{D}$ molecules on the PowerWall. For the demos, Protein Data Bank (PDB) [24, 25] files were converted to VRML for visualization and Viegen [26] was used for visualization and manipulation of the models. The CAVE demo included visualization of Oxy-haemoglobin (PDB id: 1GZX), Deoxy human haemoglobin (PDB id: $1 \mathrm{~A} 3 \mathrm{~N}$ ) and the molecular architecture of the rotary motor in ATP synthase from yeast mitochondria (PDB id: 1QO1). PowerWall demos included Insulin (PDB id: 31NS), collagen (PDB id: 1BKV) and the molecular architecture of the rotary motor in ATP synthase from yeast mitochondria (PDB id: 1QO1).

\section{RESUlTS AND DISCUSSION}

The evaluation consisted of a one page questionnaire with concise questions on the day of the students' visit to get the students' feedback on what technologies they preferred and to provide ground for future work. A post evaluation was later on conducted two months after the students' visit. The purpose of the second questionnaire was to assess how much the students could remember from all the new technologies to which they were exposed.

The results of the first evaluation showed that $46 \%$ of the students preferred the VR demos compared to only $37 \%$ who preferred the laboratory demos while $17 \%$ did not have any preference, as depicted in Fig. 1. Likewise, the post evaluation results, depicted in Fig. 2, showed that a remarkable number of students were able to remember the VR based demos compared to the different biology based demos that they were given. $88 \%$ of students could remember what they visualized in the CAVE and $48 \%$ for the PowerWall compared to only $24 \%, 48 \%$ and $16 \%$ for the Transcriptomics DNA sequencing, Mass Spectrometry laboratory and Structural Biology Unit Crystallography respectively.

Based on these results, two main conclusions can be drawn. Firstly, experience helps in retention of knowledge better, hence adding another proof to Youngblut's [22] concept. Also, the students are more interested with new technologies, since these spark their interests.

\section{CONCLUSION AND FUTURE WORK}

In this paper, a study of VR along with lab based technologies was presented, whereby school students were introduced to these technologies as a learning aid. Results showed that most students remembered what they saw in the VR context and this concludes that VR is a more memorable learning experience than the laboratory based demonstrations for students. Since students were able to recollect more what they saw in the CAVE and on the PowerWall, this cutting edge technology can be fully

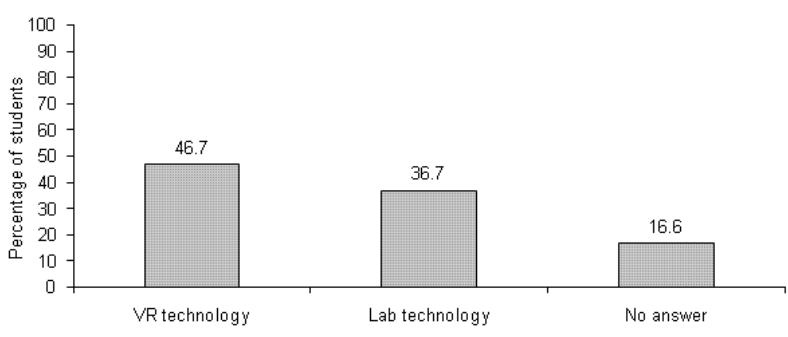

Figure 1. Preference for different technologies among study group (in percentage).

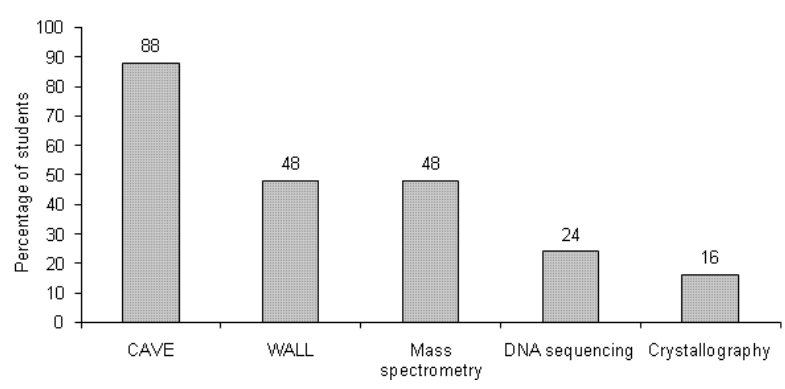

Figure 2.

Technologies remembered by the study group (in percentage).

tapped to enhance the learning process. These can be used along with the traditional teaching methods.

Future work involves a more profound study involving a larger group of students from various schools in Reading. The study will be extended for undergraduates students in the University of Reading, studying STEM subjects. This will give us a subject group large enough to compare our present results with.

Further studies will focus more on usability and ergonomics. It is anticipated to add further utilities to the visualization in the CAVE and an in-house application is being built for this purpose. More subtle navigation and manipulation will also be developed for the CAVE application to allow a more intuitive learning experience for the students.

We understand that the CAVE and PowerWall VR technologies can be expensive and not accessible to students in the school, we are therefore planning on introducing the students to the Augmented Reality (AR) technology. This technology is simply a representation of a simulation in the real word, superimposing virtual images on real objects. AR is more accessible, less costly and can be used more frequently. With this technology, teachers will be able to easily specify the molecular structures they want to show to the class and can use see-through Head Mounted Displays (HMDs) to visualize the structure.

\section{ACKNOWLEDGMENT}

We would like to thank Dr. Catherine Crawford and Mrs. Mary Heath from Kendrick School, Reading, for their useful suggestions. We also wish to acknowledge the contribution of all the students who collaborated in this preliminary study.

\section{REFERENCES}

[1] D. Laurillard, "E-learning in higher education," in Changing Higher Education: The Development of Learning \& Teaching, P. Ashwin, Ed. Oxon: Routledge, 2006, pp. 71-84. 
[2] OfCom, Office of Communication, "Communications Market Report," OfCom, Aug 2008. [Online]. Available: http://www.ofcom. org.uk/research/cm/cmr08/foreword. [Accessed: 20 September 2008].

[3] M. Conner, et al., "Learning: the critical technology," Wave Technologies International, Inc., Missouri, USA, Tech. Rep. LCTYWPLT-AXXXA 1995.

[4] K. Willing, "Learning styles in adult migrant education," The National Centre for English Language Teaching and Research (NCELTR), Sydney, Research Series 4, Australia, 1993.

[5] D.A. Kolb, "The learning style inventory," McBer and Company, Boston, Ma, Tech. Rep. 1976.

[6] D.A. Kolb, "Learning styles and disciplinary differences," in The Modern American College, A.W. Chickering, Ed., San Francisco: Jossey-Bass, 1981, pp 232-255.

[7] R.R. Sims and S.J. Sims, Ed., The Importance of Learning Styles: Understanding the Implications for Learning, Course Design, and Education. Westport, CT: Greenwood Press, 1995.

[8] Office of Faculty and Teaching Assistant Development (FATD), "Teaching at the Ohio State University: A Handbook," Ohio State University, 2001. [Online]. Available: http://ftad.osu.edu/ Publications/TeachingHandbook/. [Accessed: 30 August 2008].

[9] S.L. Dexter, R.E. Anderson, and H.J. Becker, "Teachers' views of computers as catalysts for changes in their teaching practice $<$ " Journal of Research on Computing in Education, vol. 3, pp. 221239, 1999.

[10] M.J. Albright and D.L. Graf, Ed., "Teaching in the information age: The role of educational technology," in New Directions for Teaching and Learning, no. 51. San Francisco: Jossey-Bass, 1992.

[11] J.V. Ebenezer and S. Connor, Learning to Teach Science: A Model for the $21^{\text {st }}$ Century. New Jersey, Ohio: Prentice Hall, 1998.

[12] S. Wiske, "A new culture of teaching for $21^{\text {st }}$ century," in The Digital Classroom: How Technology is Changing the Way we Teach and Learn, D.T.Gordon, Ed. Cambridge, MA: The Harvard Education Letter, 2000, pp 69-77.

[13] V.M. Williamson and M.R. Abraham, "The effects of computer animation on the particulate mental models of college chemistry students," Journal of Research in Science Teaching, vol. 32, no. 5, pp. 521-534, 1995.

[14] D.W. Hall., "Computer-based animations in large-enrollment lectures: Visual reinforcement of biological concepts," Journal of College Science Teaching, vol. 25, pp 421-425, 1996.

[15] A. Bain, and K. Ross, "School reengineering and SAT-1 performance: A case study," International Journal of Education Reform, vol. 9, no. 7, pp. 148-153, 2000.

[16] J. Schacter, "The Impact of education technology on student achievement: What the most current research has to say," Milken Exchange on Education Technology, 1999. [Online]. Available:
http://www.mff.org/pubs/ME161.pdf. [Accessed: 20 September 2008]

[17] J. Piaget, The child's conception of the world. Towota, NJ: Littlefield Adams, 1972.

[18] R. Karplus, "Science teaching and the development of reasoning," Journal of research in Science Teaching, vol. 14, pp. 169-175 1977.

[19] B.G. Witmer and M.J. Singer, "Measuring presence in virtual environments: a presence questionnaire," Presence, vol. 7, no. 3, pp 225-240, 1998.

[20] C. Cruz-Neira, S.J. Sandin, T.A. DeFanti, R.V. Kenyon, and J.C Hart, "The CAVE: Audio visual experience automatic virtual environment," Communications of the ACM, vol. 35 pp. 64-72, 1992.

[21] W. Winn, "The impact of three-dimensional immersive virtual environments on modern pedagogy," University of Washington, HITL, Tech. Rep. R-97-15, 1997.

[22] C. Youngblut, "Educational Uses of Virtual Reality Technology," $V R$ in the Schools, vol. 3, no.1, 1997.

[23] M. Heim, The Metaphysics of Virtual Reality, New York: Oxford University Press, 1993.

[24] F.C. Bernstein, et al., "Protein Data Bank: A computer-based archival file for macromolecular structures," Journal of Molecular Biology, vol. 112, no. 3, pp 534-542, 1977.

[25] H.M. Berman, et al., "The Protein Data Bank," Nucleic Acids Research, vol. 28, pp 235-242, 2000.

[26] A. Haffegee, "VieGen: an accessible toolset for the configuration and control of virtual environments," PhD Thesis, University of Reading, March 2008

\section{AUTHORS}

T. Nadan is with the School of Systems Engineering, University of Reading, Reading, UK (e-mail: t.nadan@reading.ac.uk).

V.A. Alexandrov is with the School of Systems Engineering, University of Reading, Reading, UK (e-mail: v.n.alexandrov@reading.ac.uk).

R. Jamieson graduated from the University of Reading, Reading, UK.

K. Watson is the head of the Structural Biology Unit, School of Biological Sciences, University of Reading, Reading, UK (e-mail: k.a.watson@reading.ac.uk).

The work was partly funded by the University of Reading, UK. Manuscript received 27 August 2010. Published as resubmitted by the authors March $1^{\text {st }}, 2011$ 